\title{
Microlearning in Educating Healthcare Professionals
}

\author{
Asle Fagerstrøm ${ }^{1,}$, , Marit Gulliksen ${ }^{2, b}$ and Tor-Morten Grønli ${ }^{1, c}$ \\ ${ }^{1}$ Westerdals Oslo School of Arts, Communication and Technology (Faculty of Technology), \\ Christian Kroghs Gate 32, 0186 Oslo, Norway \\ ${ }^{2}$ Oslo and Akershus University College (Department of Behavioral Science), Postboks 4 St. Olavs \\ plass, 0130 Oslo, Norway \\ aasle.fagerstrom@westerdals.no, ${ }^{\mathrm{b}}$ marit.gulliksen@gmail.com, ${ }^{\mathrm{c} t m g @ w e s t e r d a l s . n o ~}$
}

\begin{abstract}
Keywords: microlearning, mobile learning, gamification, precision teaching, healthcare professionals, experiment.
\end{abstract}

\begin{abstract}
The aim of this study was to test the impact of the use of microlearning in educating healthcare professionals. A mobile learning application was developed consisting of 20 flip cards with questions and answers. The learning program was related to a vital paragraph regulating healthcare professionals working with mentally and socially handicapped people in Norway. A between-subjects design was used with a randomized selection divided into one control group and two test groups. Both test groups used the mobile learning app. In addition, one of the test groups used social media. The control group was given ordinary teaching. Level of knowledge (dependent variable) was measured in a pre-test before the intervention and in a post-test after the intervention. Results show that level of knowledge for Test Group 1 and Test Group 2 increased compared to level of knowledge for the Control Group. This study demonstrates that behavioral principles in gamification and precision teaching can increase learning. Our conclusion is that microlearning may give a more effective learning process in some situations. Implications for healthcare educators as well as suggestions for future research are given.
\end{abstract}

\section{Introduction}

E-learning is defined as the dissemination of educational knowledge over the Internet synchronously and asynchronously [1]. This makes e-learning a sub-category of technology-based education, which includes a number of learning activities conducted on the Internet, of which mobile learning is one part. Mobile technology such as smart phones and tablets are frequently used in learning contexts. Mobile learning is defined as: "Learning across multiple contexts, through social and content interactions, using personal electronic devices." [2]. Microlearning is a learning approach that focuses on relatively small learning units and short-term learning activities [3]. The advantages of using mobile technology in microlearning is primarily that it is possible for the students to obtain information regardless of time and place. With the use of mobile technology students can study when and where they want [4;5]. This opens up new possibilities for learning.

Gamification is, according to Deterding et al., [6], the use of game design elements in a non-game context. Gamification has been used in a learning context to develop skills such as memory and problem solving for both young and old [7]. The difference between traditional classroom lecturing and gamification is that gamification initiate interactivity. Goal orientation, reward systems and progression are important basic elements of gamification [8]. Behavioral consequences is immediate presented in gamification. Immediate positive consequences contingent on behavior will, most probably, function as a stimulus to "replay", and learn more [7]. Gamification is, thus, an emergent change in learning strategy that could lead to changes in education practice in a positive way [7].

According to Lindsley [9], precision teaching is a teaching method that is "basing educational decisions on changes in continuous self-monitored performance frequencies displayed on 'standard celeration charts."' The idea in precision teaching is that when a student learn, the rate of correct responses and speed is important. Correct responses and speed are, therefore, measured and charted 
in a precision teaching program. The goal is to achieve behavioral fluency, which is [10]: a "combination of accuracy plus speed of responding that enables competent individuals to function efficiently and effectively in their natural environments".

Using elements from games in combination with precision teaching and mobile technology when designing a microlearning program can provide a more effective learning. The aim of this study is, thus, to test the impact of the use of microlearning in educating healthcare professionals.

\section{Method}

Thirty healthcare professionals working with mentally and socially handicapped people in Norway was invited to participate in the study. Criteria for participating was that they had a smart phone and have access to Facebook. There were 15 males and 15 females with an age range from 18 to 60 years. The participants were recruited from different departments. Eighteen of the participants are assistants (unskilled), 10 are skilled health workers, and 2 experienced workers with a college background. Some of the participants was immigrants, and did not speak fluent Norwegian.

We developed a mobile learning app consisting of 20 flip cards with questions and answers related to a vital paragraph regulating healthcare professionals work with mentally and socially handicapped people in Norway. The paragraph that workers have to know regulates the use of coercion when working with mentally and socially handicapped peoples. The workers are legally required to know its content and its use in practice. The gamification elements built in the app was to answer as many questions as possible in the shortest possible time. For each of the 20 flip cards, a question related to the paragraph was presented on the first page, and the correct answer was given when the card was turned. See Fig. 1 for an example of the flip cards. The test could be repeated to improve performance. The app was available for the participants during the test weeks. In addition, a closed Facebook group was created, where one of the test group could participate share results, and, comment and like each other's test performance.

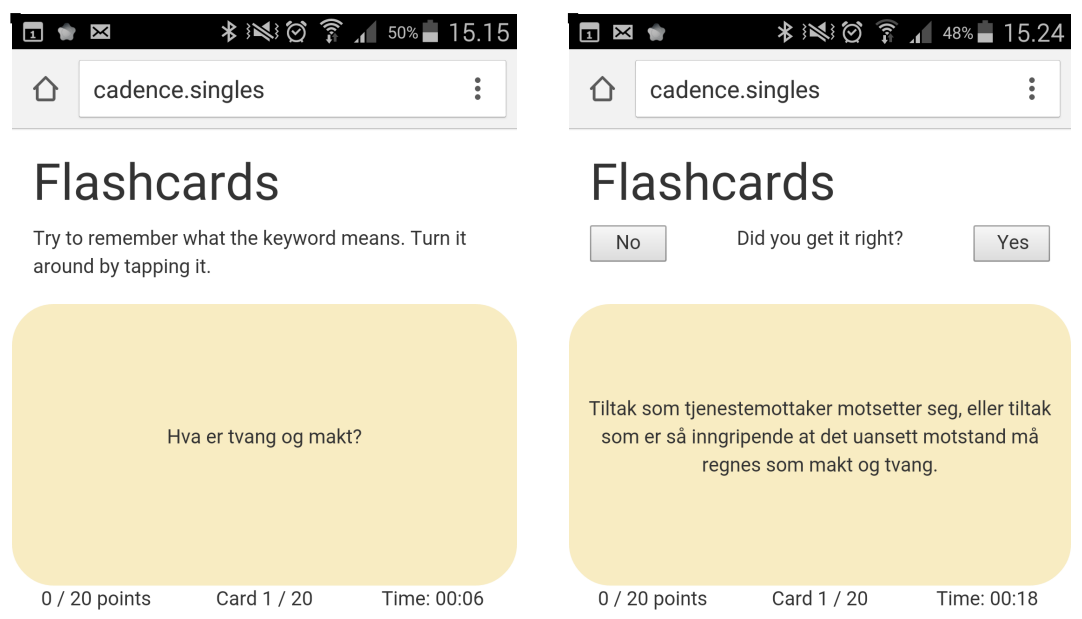

Fig. 1. Application with flip cards that could be downloaded on smart phones.

On the first page (left picture) the question is presented, and the correct answer appears when the card is turned (right picture). The left corner indicates points and in the right corner one can monitor the time spent on answering all 20 questions. 
A between-subjects design was used with a randomized selection divided into one control group and two test groups. The Control Group was given ordinary teaching, and was held each Monday in a three weeks' period. The training for the Control Group consists of lecturing and workshops. Both test groups used the mobile app. In addition, Test Group 2 used, however, in addition social media where they could publish their result from the mobile learning app and communicate with the other members in that group. A gamification element was facilitated on the Facebook group in that participants could compete with each other about which had most correct answers in shortest time spent. A pre- and posttest was conducted to measure participants' knowledge related to the paragraph. Correct answers in percentage, median, and standard deviation was calculated, and used to compare performance between the groups.

\section{Findings}

Results from the present study show that level of knowledge for Test Group 1 and Test Group 2 increased considerably compared to level of knowledge for the Control Group (see Table 1).

Table 1 Results for Control Group, Test Group 1 and Test Group 2 for pre-test and post-test. Numbers are correct answers from the 20 questions.

\begin{tabular}{|c|c|c|c|c|c|c|}
\hline \multirow[t]{2}{*}{ Participants } & \multicolumn{2}{|c|}{ Control Group } & \multicolumn{2}{|c|}{ Test Group 1} & \multicolumn{2}{|c|}{ Test Group 2} \\
\hline & Pre-test & Post-test & Pre-test & Post-test & Pre-test & Post-test \\
\hline 1 & 7 & 7 & 2 & 13 & 2 & 15 \\
\hline 2 & 5 & 2 & 9.5 & 19 & 8 & 17 \\
\hline 3 & 4 & 5 & 5 & 17 & 5 & 16 \\
\hline 4 & 7 & 8 & 3 & 13 & 7 & 13 \\
\hline 5 & 6 & 4 & 9 & 19 & 3 & 11 \\
\hline 6 & 6 & 9 & 4.5 & 19 & 4 & 13 \\
\hline 7 & 3 & 3 & 0 & 7 & 6 & 17 \\
\hline 8 & 6 & 6 & 4 & 9 & 6 & 15 \\
\hline 9 & 6 & 8 & 7 & 9 & 7 & 15 \\
\hline 10 & 2 & 2 & 4 & 0 & 6 & 15 \\
\hline $\begin{array}{l}\text { Correct answers in } \\
\text { percentage }\end{array}$ & $26 \%$ & $29 \%$ & $23 \%$ & $70 \%$ & $25 \%$ & $76 \%$ \\
\hline Median & 5 & 5 & 4 & 13 & 4.5 & 16 \\
\hline SD & 1.7 & 2.1 & 2.5 & 4.6 & 1.6 & 2.5 \\
\hline
\end{tabular}

Table 1 shows that the Control Group had 26\% correct answers in the pre-test and 29\% correct answers in the post-test. Test Group 1 had 23\% correct answers in the pre-test and $70 \%$ in the posttest, and, Test Group 2 had 25\% correct answers in the pre-test and 76\% answers in the post-test. The participants were very positive when we asked them about their opinion regarding using mobile phone and flip cards as part of a learning program. One participant answer that "the use of games on smart phones is accessible and easy to use." Another participant commented that the questions sometime was difficult to understand, as for example "For those of us who do not have Norwegian as the first language, some of the questions could be misunderstood."

\section{Concluding Comments}

The aim of this study was to test the impact of microlearning in educating healthcare professionals. Results from a between-group experiment shows that level of knowledge for the two test groups increased compared to level of knowledge for the control group. Participants also report that the microlearning program was a success. Our conclusion is that behavioral principles such as gamification [6] and precision teaching [9], together with a mobile learning program, gives an effective microlearning process in educating healthcare professionals. 
In microlearning, learning take place through small learning units and short-term learning activities [3]. Short-term learning sequences can be combine into larger courses. Findings from our study demonstrates that engaging in this type of learning activities can easily create learning communities, where it is the process that initiate the learners' activity [3]. Findings from the present study show that principles from precision teaching, focusing on accuracy and speed [9], and, social reinforcement given in social media, is elements that increase the participants learning. Finally, technology has changed how we communicate, acquire knowledge, and, develop new ideas [2]. The present study demonstrate that a mobile application made it possible for the participants to participate in the micorlearning program regardless of time and place. Compared to traditional learning programs used within in educating healthcare professionals such as presentations on meetings, the use of mobile learning may increase participation in the learning program.

A follow up study should recruit about 20 participants in each group, and from different geographical areas. More participants in each group can increase internal validity, and in addition, make it possible to calculate significant values. A geographical distribution would also help to increase internal validity in that participants do not communicate with each other. I follow up study should carefully facilitate the gamification element on Facebook since we experienced that the interaction was low for Test Group 2.

\section{References}

[1] D. R. Garrison, Cognitive presence for effective asynchronous online learning: The role of reflective inquiry, self-direction and metacognition, Elements of quality online education: Practice and direction, 4 (2003), 47-58.

[2] H. Crompton, A historical overview of mobile learning: Toward learner-centered education, in: Z. L. Berge \& L. Y. Muilenburg (Eds.), Handbook of mobile learning Florence, KY: Routledge, 2013, pp. 3-14.

[3] C. McLoughlin \& M. J. Lee, Mapping the digital terrain: New media and social software as catalysts for pedagogical change. Proceedings ascilite, Melbourne, 2008, pp. 641-652.

[4] G. Morar, C. Muntean \& N. Tomai, An Adaptive M-learning Architecture for Building and Delivering Content based on Learning Objects. Economy Informatics Journal, 10 (2010), 6373.

[5] C. Evans, The effectiveness of m-learning in the form of podcast revision lectures in higher education, Computers \& Education, 50 (2008), 491-498.

[6] S. Deterding, D. Dixon, R. Khaled, \& L. Nacke. From Game Design Elements to Gamefullness: Defining "Gamification". Paper presented at the MindTrek'11, Tampere, Finland, (2011).

[7] Z. H. Morford, B. N. Witts, K. J. Killingsworth \& M. P. Alavosius, Gamification: The Intersection between Behavior Analysis and Game Design Technologies. The Behavior Analyst, 37 (2014), 25-40.

[8] Glover, Play as you learn: gamification as a technique for motivating learners, in: J. Herrington, A. Couros and V. Irvine (Eds.), Proceedings of World Conference on Educational Multimedia, Hypermedia and Telecommunications. Chesapeake, VA, AACE, 2013, pp. 1999-2008.

[9] R. Lindsley, Precision teaching: Discoveries and effects, Journal of Applied Behavior Analysis, 25 (1992), 51-57.

[10] C. Binder, Behavioral fluency: Evolution of a new paradigm, The Behavior Analyst, 19 (1996), 163-197. 